\title{
A Rapid ELISA Test for Detection of Human Paraproteins
}

\author{
Irute Girkontaite', Margarita Leckiene ${ }^{1}$, Igor Trociuk ${ }^{2}$, Vilmantas Giedraitis ${ }^{1}$ and Mykolas Mauricas ${ }^{1}$ \\ 1 Institute of Biotechnology, Vilnius, Lithuania \\ 2 Vilnius University Hospital, Vilnius, Lithuania
}

Summary: A rapid ELISA test for detection, characterization and quantification of human paraproteins was developed. The proposed method is a sandwich ELISA, where the capture antibody is specific for a given heavy chain $(\gamma, \alpha$ or $\mu)$ and the labelled antibody is specific either for $\kappa$ or for $\lambda$ light chain. Both standard and patient sera are tested with all six possible antibody combinations. Each paraprotein produces a significant increase in titre (as compared with standard) only when tested with the relevant pair of antibodies. This enables the determination of the isotype and light chain type of the paraprotein and the evaluation of its relative quantity in patient serum. The accuracy of the assay (relative deviation) varies from 0.04 for $\gamma \lambda$ to 0.19 for $\alpha \kappa$. The cut-off values for each type of polyclonal immunoglobulin were determined with 200 healthy donor sera. 103 patient sera were analysed. ELISA data are in good agreement with $\mathrm{M}$-component and other clinical data.

\section{Introduction}

Detection and quantification of monoclonal paraproteins in patient sera are diagnostically important when a malignancy of the lymphoid system is suspected. Currently, the following methods are employed to detect paraproteins:

serum protein electrophoresis (1), serum immunoelectrophoresis (2), two-dimensional electrophoresis $(3-5)$, high-resolution agarose gel electrophoresis (6), immunoblotting, immunofixation (4, 7-9).

The expression of peripheral blood B-cell surface or intracellular immunoglobulins measured by an immunofluorescence technique is also used to identify the malignant B-cell clone $(10,11)$. The classification of paraproteins according to their heavy and light chain requires immunoelectrophoresis, immunoblotting, immunofixation or immunofluorescence, whereas these methods are not very useful for quantification. The amount of paraprotein in the serum is usually calculated from the relation of paraprotein in serum electrophoresis and total serum protein concentration. Most of these methods, though well established and validated, are laborious and time-consuming. In this paper we present a simple and rapid ELISA test, that enables detection of the myeloma product, identification of its class, light chain type and quantity in patient serum.

\section{Materials and Methods}

Monoclonal antibodies

All monoclonal antibodies used in this study were produced, purified and characterised in our laboratory $(12,13)$. Hybridomas were established by the Köhler-Milstein technique (14). BALB/c mice were immunised with mixed human immunoglobulins, isolated IgG Fc fragments or purified IgA, and the spleen cells were fused with myeloma cells. Indirect ELISA was used to select positive clones.

Monoclonal antibodies were purified from ascites by ammonium sulphate precipitation and affinity chromatography on protein $A$ Sepharose (15). The purity of antibody preparations, tested in SDSpolyacrylamide gel, was over $99 \%$. Horseradish peroxidase was linked to antibodies by a periodate method (16). Anti- $\gamma$ and anti- $\alpha$ monoclonal antibodies reacted with all subclasses of polyclonal and monoclonal IgG and IgA.

Sera

Blood samples were obtained by venipuncture and sera were stored at $-20^{\circ} \mathrm{C}$. Standard pooled serum was collected from 50 healthy donors. The immunoglobulin concentrations in standard pooled serum were determined both by radial immunodiffusion (17) and ELISA (18). IgG, IgA and IgM concentrations were $14.7 \mathrm{~g} / 1,2.07$ $\mathrm{g} / \mathrm{l}$ and $1.24 \mathrm{~g} / \mathrm{l}$ respectively. No paraproteins were detected in the pooled standard by agarose gel scanning (1). Standard sera did not possess antibodies against cytomegalovirus, hepatitis $\mathrm{B}$ and $\mathrm{C}$ and HIV type I, as established with Abbott's antibody kits.

Test sera samples were collected from patients of the Haematology Department of Vilnius University Hospital. A total of 103 patient sera was tested.

\section{Enzyme linked immunosorbent assay}

Dynatech Immunolon 96-well plates were used to perform ELISA tests. Purified monoclonal antibodies $(5 \mathrm{mg} / \mathrm{l}$ in $50 \mathrm{mmol} / \mathrm{l} \mathrm{Na}$ phosphate buffer $\mathrm{pH} 6.0$ ) were pipetted into the plates, $0.1 \mathrm{ml}$ per well, and incubated overnight at $4{ }^{\circ} \mathrm{C}$. Wells were further blocked with $10 \mathrm{~g} / 1$ albumin in phosphate-buffered saline $(0.15 \mathrm{ml} / \mathrm{svell}$, $30 \mathrm{~min}$, room temperature) and washed ( 3 times with phosphatebuffered saline). Eight serial 3-fold dilutions of serum samples, both standard and patient, were prepared in phosphate-buffered saline and $0.1 \mathrm{ml}$ of each dilution was applied to the wells. The starting serum dilutions were as follows: $1: 30000$ for anti- $\gamma-$ anti- $\kappa$ sandwich, $1: 4000$ for anti- $\gamma-$ anti- $\lambda$ sandwich and $1: 1000$ for the other four monoclonal antibodies combination. To achieve acceptable precision the $1: 30000$ and $1: 4000$ dilutions were prepared in two steps, using $1: 1000$ as an intermediate dilution. Sera 
were incubated $60 \mathrm{~min}$ at room temperature, plates were washed (threc times in phosphate-buffered satine with $0.5 \mathrm{~g} / \mathrm{l}$ Tween 20 ) and $0.1 \mathrm{ml}$ of appropriate horseradish peroxidase conjugates (anti$\kappa$ or anti- $\lambda$ 1:1000 in phosphate-buffered saline-Tween 20) was added. Plates were incubated for $30 \mathrm{~min}$ at room temperature and washed (10 times, phosphate-buffered saline-Tween 20). Bound horseradish peroxidase was detected with $o$-phenylenediamine $(0.1$ $\mathrm{ml} / \mathrm{well}, 0.5 \mathrm{~g} / \mathrm{l} o$-phenylenediamine and $17.6 \mathrm{mmol} / \mathrm{l} \mathrm{H}_{2} \mathrm{O}_{2}$ in 25 $\mathrm{mmol} / / \mathrm{CH}_{3} \mathrm{COONa}, \mathrm{pH}$ 5.5). All colour reactions were stopped with $2 \mathrm{~mol} / 1 \mathrm{H}_{2} \mathrm{SO}_{4}(0.05 \mathrm{ml} /$ well $)$ and the absorbance was measured in a Titertek Multiscan plate reader at $492 \mathrm{~nm}$.

\section{Evaluation of ELISA data}

The quantity of immunoglobulin population is calculated in the following way: we have pooled healthy donors sera used as a control standard serum. The quantity of each Ig type $(\gamma \kappa, \gamma \lambda, \alpha \kappa, \alpha \lambda$, $\mu \kappa$ or $\mu \lambda)$ is set 1 arbitrary units. Tested sera are compared to this standard and the quantity of each Ig population $(\gamma \kappa, \gamma \lambda, \alpha \kappa, \alpha \lambda$, $\mu \kappa$ or $\mu \lambda$ ) in patients sera were calculated according the formula:

where

$$
\text { Quantity of Ig population }=\left(\mathrm{T}_{50} \text { of } \mathrm{Ps} / \mathrm{T}_{50} \text { of } \mathrm{Ss}\right)
$$

$$
\text { (arb. units), }
$$

$\mathrm{T}_{50}$ : serum dilution, corresponding to $50 \%$ of maximal absorbancy at $492 \mathrm{~nm}$;

Ps: patient serum;

Ss: standard serum.

If the particular Ig type for example $\gamma \kappa$, in the individually tested serum is underrepresented, as compared with the standard, then we get a quantity value $<1$ arb. unit. On the contrary, if this given Ig type is increased, we would have a quantity value $>1$ arb. unit. Even in healthy donors sera the quantity values vary significantly. In patients with paraproteinaemia, where increase in particular Ig type is enormously large, the calculated quantity values can reach 100 arb. units or even more.

\section{Assay accuracy and reproducibility}

To determine the assay accuracy sera were tested in five replicates in the same ELISA plate. The test accuracy was expressed as the relative standard deviation ( $\mathrm{CV}, \%)$ of absorbances within experiments. The reproducibility of the test was evaluated as betweenrun relative deviation of the arbitrary units of the same serum, tested in five different experiments. The ELISA test was performed and the arbitrary units calculated as described above.

\section{Determination of other diagnostic properties}

The serum M-component was detected by agarose gel scanning (1). Total serum protein was quantified according to Lowry (19). Bone marrow punctate cell slides were prepared, stained with Giesma (2) and examined microscopically. Total cells, plasma cells and lymphocytes were counted and their fraction calculated.

\section{Results}

The present approach is based on the consideration that all immunoglobulins, detected in sandwich anti- $\gamma$-anti$\kappa$, belong to the $\gamma \kappa$ immunoglobulin population; the anti- $\gamma$-anti- $\lambda$ monoclonal antibodies pair detects all $\gamma \lambda$ immunoglobulins in tested sera, and so on. For each pair of monoclonal antibodies the end-point of the serum titration curve was supposed to reflect the arbitrary unit of the respective immunoglobulin type $(\gamma \kappa, \gamma \lambda, \alpha \kappa, \alpha \lambda, \mu \kappa$ or $\mu \lambda)$. The assay accuracy and reproducibility characteristics were studied and the data are documented in the table 1.

\begin{tabular}{|c|c|c|c|c|}
\hline \multicolumn{2}{|c|}{ Antibodies } & \multirow[t]{2}{*}{$\begin{array}{l}\text { Paraprotein } \\
\text { detected }\end{array}$} & \multicolumn{2}{|c|}{$\begin{array}{l}\text { Coefficient of } \\
\text { variation (\%) }\end{array}$} \\
\hline Capture & Labelled & & $\begin{array}{l}\text { within- } \\
\text { Fun }\end{array}$ & $\begin{array}{l}\text { between- } \\
\text { run }\end{array}$ \\
\hline anti- $\gamma$ & anti-K & $\gamma \kappa$ & 7.69 & 9.94 \\
\hline anti- $\gamma$ & anti- $\lambda$ & $\gamma \lambda$ & 4.38 & 19.3 \\
\hline anti- $\alpha$ & anti-K & $\alpha \kappa$ & 9.72 & 19.0 \\
\hline anti- $\alpha$ & anti- $\lambda$ & $\alpha \lambda$ & 11.2 & 13.3 \\
\hline anti- $\mu$ & anti-K & $\mu \kappa$ & 8.95 & 16.0 \\
\hline anti- $\mu$ & anti- $\lambda$ & $\mu \lambda$ & 9.78 & 19.5 \\
\hline
\end{tabular}

Tab. 1 Assay accuracy and reproducibility

To determine the cut-off values for identification of monoclonal paraprotein component in the patient, values of arbitrary units for each type of immunoglobulin were calculated for sera from 200 healthy donors. The cut-off values (mean arbitrary units plus $3 \times \sigma$ ) determined for each pair of monoclonal antibodies are presented in table 2 .

Tab. 2 Cut-off values for detection of the immunoglobulin type

\begin{tabular}{|c|c|c|c|c|}
\hline \multicolumn{2}{|c|}{ Antibodies } & \multirow{2}{*}{$\begin{array}{l}\text { Ig } \\
\text { type }\end{array}$} & \multirow{2}{*}{$\begin{array}{l}\text { Mean } \\
\text { (arb. units } \\
\pm \text { SD) }\end{array}$} & \multirow{2}{*}{$\begin{array}{l}\text { Cuf-off } \\
\text { (mean of } \\
\text { arb. units } \\
+3 \sigma \text { ) }\end{array}$} \\
\hline Capture & Labelled & & & \\
\hline anti- $\gamma$ & anti-k & $\gamma \kappa$ & $1.28 \pm 0.57$ & 3.00 \\
\hline anti- $\gamma$ & anti- $\lambda$ & $\gamma \lambda$ & $1.00 \pm 0.32$ & 1.98 \\
\hline anti- $\alpha$ & anti-K & $\alpha K$ & $1.32 \pm 0.78$ & 3.68 \\
\hline anti- $\alpha$ & anti- $\lambda$ & $\alpha \lambda$ & $1.02 \pm 0.62$ & 2.88 \\
\hline anti- $\mu$ & anti-K & $\mu \kappa$ & $1.15 \pm 0.40$ & 2.37 \\
\hline anti- $\mu$ & anti- $\lambda$ & $\mu \lambda$ & $1.09 \pm 0.65$ & 3.06 \\
\hline
\end{tabular}
in serum

Sera with values of arbitrary units exceeding the cut-off value in one or two combinations of monoclonal antibodies were considered to be paraprotein-positive or double positive (possessing two paraproteins). The sandwich type with an increased value of arbitrary units indicated the heavy chain class and light chain type of the detected paraprotein(s). For example, if an increase of arbitrary unit values was determined using anti- $\gamma$ capture

Tab. 3 Paraprotein detection in patient sera by monoclonal anti-

\begin{tabular}{|c|c|c|c|}
\hline \multirow[t]{2}{*}{ Disease } & \multicolumn{3}{|c|}{ Number of patients tested } \\
\hline & Total & $\begin{array}{l}\text { Paraprotein } \\
\text { positive }\end{array}$ & $\begin{array}{l}\text { Parapro- } \\
\text { tein } \\
\text { double } \\
\text { positive }\end{array}$ \\
\hline Multiple myeloma & 61 & 55 & 0 \\
\hline Monoclonal gammapathy & 5 & 5 & 0 \\
\hline Waldenström macroglobulinaemia & 13 & 13 & 0 \\
\hline Other B-cell malignancies & 10 & 8 & 1 \\
\hline T-cell malignancies & 7 & 0 & 0 \\
\hline Autoimmune diseases & 7 & 0 & 0 \\
\hline
\end{tabular}
body-based sandwich ELISA 

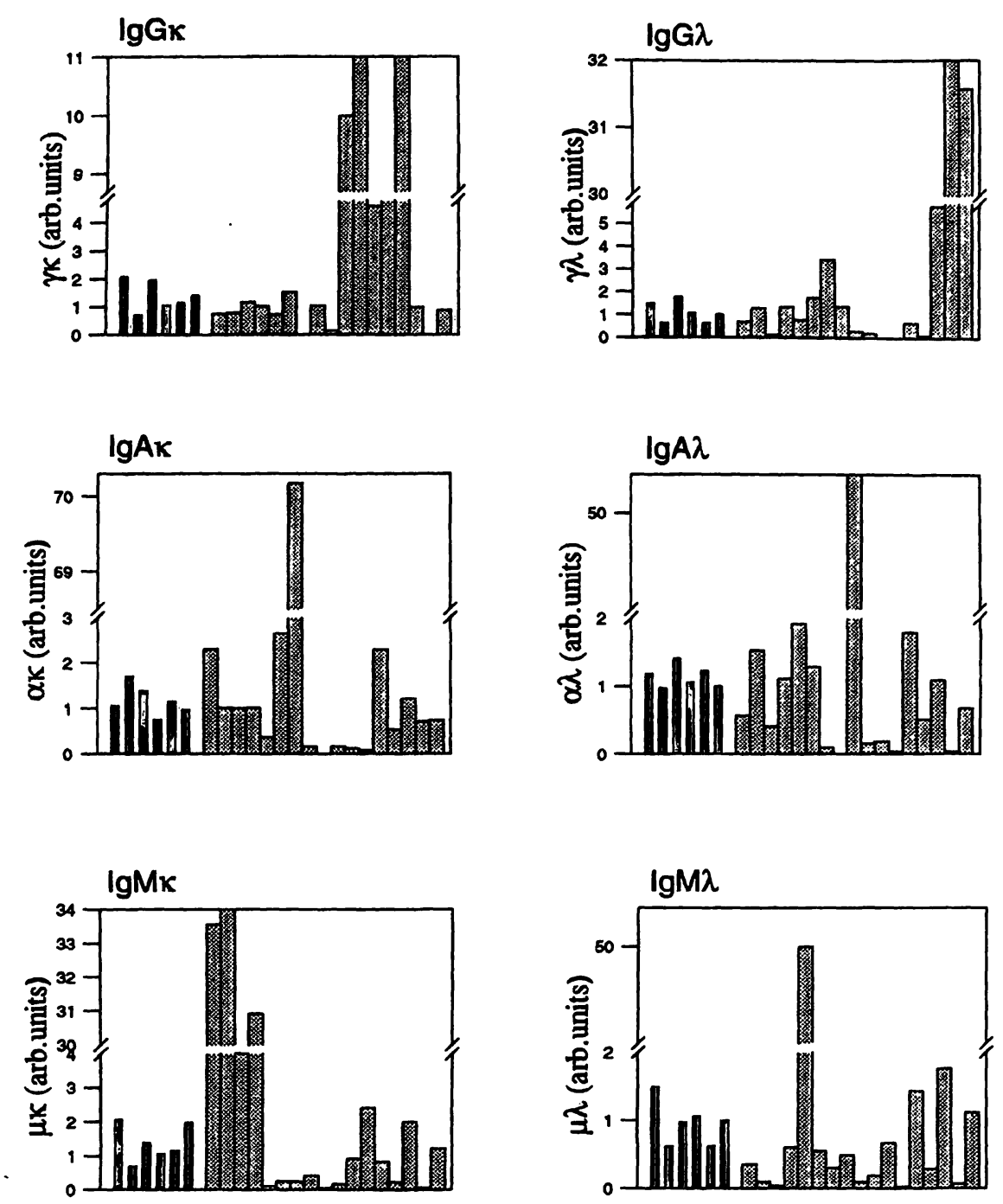

Fig. 1 The detection of monoclonal immunoglobulins using sandwich ELISA. ELISA plates were coated with heavy chain specific monoclonal antibodies. The bound immunoglobulins were quantitated with light chain specific monoclonal antibodies conjugated with horseradish peroxidase.

and anti- $\mathrm{k}$ labelled antibodies, the paraprotein was classified as $\gamma \mathrm{\kappa}$. The detection of some monoclonal Ig is shown in figure 1.

Sera of 103 patients, with B- and T-cell malignancies, other haematological diseases and autoimmune diseases were tested in the proposed ELISA system. The results are summarised in table 3.

Our data on detection and quantification of paraproteins were compared with other significant diagnostic quantities. These included: $M$ component and total protein quantity in patient sera, percent of plasma cells and lymphocytes in bone marrow punctate. This was done for all patients, and some of the data together with the final disease diagnosis are presented in table 4 . These data demonstrate a good agreement of the ELISA results with the other properties studied.

\section{Discussion}

Detection and quantification of monoclonal components, associated with certain B-cell malignancies is a well

a Immunoglobulins of healthy donors

Immunoglobulins of patients with B-cell malignancies

established routine procedure in clinical laboratories. Nevertheless these validated techniques are laborious and time-consuming. A rapid and simple ELISA test is an improvement in the clinical laboratory.

This paper presents a monoclonal antibody-based sandwich ELISA that enables the detection, classification and quantification of paraproteins in a single test. The rational of the method is as follows: immunoglobulins of a given class $(\gamma, \alpha$ or $\mu)$ are captured by immobilised class-specific antibodies and visualised with enzymelinked antibodies specific for the $\kappa$ or $\lambda$ light chain. $\mathrm{Pa}$ tient sera are tested in all six possible antibody combinations and compared with standard pooled healthy donor serum. The increase in certain immunoglobulin population $(\gamma \kappa, \gamma \lambda, \alpha \kappa, \alpha \lambda, \mu \kappa$ or $\mu \lambda)$ can be calculated. The absolute quantitation of monoclonal components cannot be achieved by the proposed ELISA, but this is not always necessary for the clinical follow up of myeloma patients. It can be easily judged from the routine laboratory values for total serum protein concentration and serum protein electrophoresis. The diagnostic value of the 


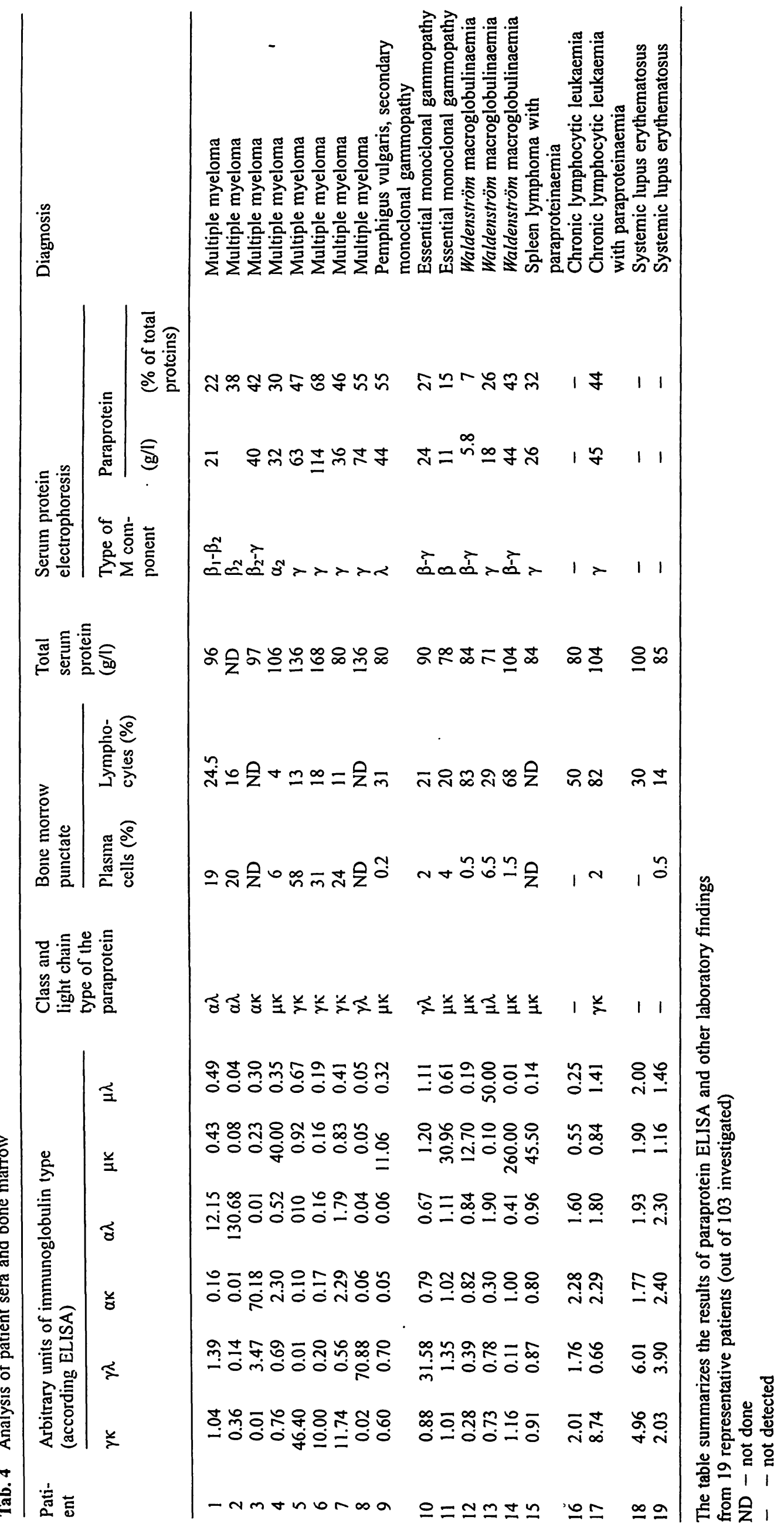


method is to measure relative changes in an individual patient. From this point of view both the methods and the mode of evaluation seem to be informative.

Clinical data for all patients included in this study were collected and correlated with the presence and relative

\section{References}

1. Jeppson JO, Laurell LB, Franzen B. Agarose gel electrophoresis. Clin Chem 1979; 25:629-38.

2. Hudson L, Hay FC. Practical immunology. Oxford: Blackwell Scientific Publications, 1989.

3. Harrison $\mathrm{HH}$, Miller $\mathrm{KL}$, Abu-Alfa A, Podlasek SJ, Jeppson, et al. Immunoglobulin clonality analysis. Resolution of ambiguities in immunofixation electrophoresis results by high-resolution, two-dimensional electrophoretic analysis of paraprotein bands eluted from agarose gels. Am J Clin Immunopathol $1979 ; 100: 550-60$.

4. Harriso HH. The "Ladder light chain" or "Pseudo-oligoclonal" pattern in urinary immunofixation electrophoresis (IFE) studies: a distinctive IFE pattern and an explanatory hypothesis relating it to free polyclonal light chains. Clin Chem 1991; 37:1559-64.

5. Harrison HH. Patient-specific microheterogeneity patterns of monoclonal immunoglobulin light chains as revealed by high resolution, two-dimensional electrophoresis. Clin Biochem 1992; 25:235-43.

6. Stemerman D, Papadea C, Martino-Saltzman D, O'Connell AC, Demaline B, Austin GE. Precision and reliability of paraprotein determinations by high-resolution agarose gel electrophoresis. Am J Clin Pathol 1989; 91:435-40.

7. Ritchie RF, Smith R. Immunofixation: III. Application to the study of monoclonal proteins. Clin Chem 1976; 22:1982-5.

8. Keshgegian AA, Pfeiffer P. Immunofixation as an adjunct to immunoelectrophoresis in characterization of serum monoclonal immunoglobulins. Clin Chim Acta 1980; 110:337-40.

9. Gerard SK, Chen KH, Khayam-Bashi H. Immunofixation compared with immunoelectrophoresis for the routine characterization of paraprotein disorders. Am J Clin Pathol 1987; 88:198-203.

10. Wainscot JS, Fey MF. Assessment of clonality in human tumors: a review. Cancer Res 1990; 50:1355-60. quantities of paraprotein in sera. The preliminary results confirm the consensus of ELISA and clinical data.

\section{Acknowledgements}

We are very grateful to Dr. R. Voll, Dr. R. Burger and Dr. R. Hallmann for helping to prepare this manuscript.

11. Reynolds WM, Williamson AM, Smith GJ, Lane AC. A simple technique for the determination of kappa and lambda immunoglobulin light chain expression by B cells in whole blood. J Immunol Meth 1992; 151:123-9.

12. Girkontaite I, Leckiene M, Mauricas M, Bumelis VA. Monoclonal antibodies to human immunoglobulins: production and characteristic. Experiment Biology 1990; 1:86-95.

13. Girkontaite I, Leckiene M, Mauricas M, Bumelis VA. Monoclonal antibodies to human mmunoglobulins $\kappa$-light chains. Biology 1994; 1:51-8.

14. Köhler G, Milstein C. Continuous cultures of fused cells secreting antibody of predefined specificity. Nature 1975; 256:495-7.

15. Hardy RR. Purification and characterization of monoclonal antibodies. In: Handbook of experimental immunology, Weir DM, editor. Oxford: Blackwell Scientific Publications, 1986; 1:13.1-13.13.

16. Boorsma DM, Streefker JG. Periodate or glutaraldehyde for preparing peroxidase conjugates? J Immunol Meth 1979; 30:245.

17. Mancini G, Carbonara AO, Hereman JF. Immunochemical quantitation of antigens by single radial immunodiffusion. Immunochemistry $1965 ; 2: 35-254$.

18. Balsys J, Bumelis VA, Girkontaite I, Leckiene M, Mauricas $\mathrm{M}$, Trociuk $\mathrm{I}$. Total and monoclonal immunoglobulin detection and quantitation in human sera by enzyme-linked immunosorbent assay. Biology 1994; 3:67-73.

19. Lowry OH, Rosenbrough NJ, Farr AL, Randall RJ. Protein measurement with the Folin phenol reagent. J Biol Chem $1951 ; 193: 265$.

Received August 28/November 28, 1995

Corresponding author: $M$. Leckiene, Institute of Biotechnology, Graiciuno 8, 2028 Vilnius, Lithuania 
$$
\text { ' }
$$ 